\title{
Mechanisms Controlling the Degradation of Poly(methyl methacrylate) Prior to Piloted Ignition
}

\author{
Sam M. Dakka ${ }^{(1)}$, Gregory S. Jackson ${ }^{(2)}$, and Jose L. Torero ${ }^{(3)}$ \\ (1) Department of Aerospace Engineering \\ (2) Department of Mechanical Engineering \\ (3) Department of Fire Protection Engineering \\ University of Maryland \\ College Park, MD20742 \\ USA
}

Colloquium: FIRE RESEARCH

Key Words: Ignition, Material Flammability, Pyrolysis

Corresponding Author: Jose L. Torero

School of Civil and Environmental Engineering

Crew Building, The King's Buildings

The University of Edinburgh

Edinburgh, EH9 3JN

UK

Telephone: 44-131-650-5723

FAX: 44-131-650-6781

e-mail: J.Torero@ed.ac.uk 


\begin{abstract}
Degradation of Type-G PMMA (Rohm and Haas) plates was studied prior to piloted ignition. The onset of pyrolysis was estimated by means of an infrared camera with an MMA filter, a small load cell, thermocouples, and flow visualization. Onset of gasification due to material pyrolysis occurs significantly earlier than piloted ignition. Therefore, models of standard test methods such as ASTM-E-1321 must incorporate pre-ignition gasification to properly model the ignition process. To better establish the mechanisms controlling the degradation process, controlled mass loss tests were conducted with shavings from the PMMA plates. Tests in nitrogen and oxygenated atmospheres were conducted with thermogravimetric analysis and evolved gas measurements using a quadrupole mass spectrometer. Results indicated a one step degradation process in pure $\mathrm{N}_{2}$ while a two-step reaction could be observed in the presence of $\mathrm{O}_{2}$. As $\mathrm{O}_{2}$ fraction increased, the onset of degradation shifted to lower temperatures but the second step correlated well with that of $\mathrm{N}_{2}$ degradation. The evolved gas measurements suggest that both reactions were limited by mass transport, with the first reaction limited by $\mathrm{O}_{2}$ diffusion into the sample. Mass transport limitations were identified by abrupt changes in the slope of production rate of evolved gases, and this indicates the importance of coupling TGA measurements with evolved gas analysis for detecting mass transport limitations. Implications of these results on interpreting material flammability tests are discussed in this paper.
\end{abstract}




\section{Introduction}

Ignition of a combustible material is commonly described as a sequence of events that starts as preheating without reactions until a pyrolysis temperature is attained. This initial process is generally characterized to as a time to pyrolysis $\left(t_{\mathrm{P}}\right)$. Upon initiation of pyrolysis, flammable gases begin to emerge from the surface until a flammable mixture is formed. This second stage in the ignition process is characterized by a mixing time $\left(t_{M}\right)$, during which the rate of fuel vapors emerging from the surface increases and subsequent mixing of these pyrolysis vapors with the surrounding air creates a flammable mixture. If the temperature of the flammable mixture rises sufficiently, then a self-sustaining exothermic reaction ignites. This last stage is characterized by an induction time $\left(\mathrm{t}_{\mathrm{I}}\right)$. The total time necessary for ignition to occur, ignition delay time, can be simply expressed as the summation of the three characteristic times; $\mathrm{t}_{\mathrm{ig}}=\mathrm{t}_{\mathrm{P}}+\mathrm{t}_{\mathrm{M}}+\mathrm{t}_{\mathrm{I}}[1]$.

In an effort to develop standard flammability criteria for materials, attempts have been made to eliminate or control the impact of environmental conditions such as ambient temperature and gas phase conditions. A simple way to minimize the impact of the gas phase conditions is to incorporate a pilot flame. The pilot eliminates the need to heat the flammable mixture by absorption of radiation or convective heat transfer from the surface and thus reduces the otherwise relatively large induction time, $t_{I}$, to near zero. Since $t_{I}$ is the component of $t_{i g}$ most strongly influenced by environmental conditions, the use of piloted ignition is preferred for flammability testing. With $\mathrm{t}_{\mathrm{I}} \approx 0$, the effective ignition time for piloted ignition becomes, $\mathrm{t}_{\mathrm{ig}} \approx \mathrm{t}_{\mathrm{P}}+\mathrm{t}_{\mathrm{M}}$, and ignition will occur as soon as a flammable mixture is established.

Traditionally, the mixing time has been considered negligible compared to the time taken for the solid temperature to rise from ambient to the pyrolysis temperature $\left(t_{P}>t_{M}\right)$. Hence, it is common in material flammability testing to consider the time to attain the pyrolysis temperature as the ignition delay time $\left(\mathrm{t}_{\mathrm{ig}} \approx \mathrm{t}_{\mathrm{P}}\right)$ and the temperature for the onset of pyrolysis $\left(\mathrm{T}_{\mathrm{P}}\right)$ as the ignition temperature $\left(\mathrm{T}_{\mathrm{ig}} \approx \mathrm{T}_{\mathrm{P}}\right)$. Thus, the piloted ignition delay time can be estimated by modeling the heating process of an inert solid until it reaches a specific ignition or pyrolysis temperature at the surface. The most commonly employed solution is that of a semiinfinite solid heated by a combination of external radiation and natural convection. This approach is the basis of the LIFT Standard (ASTM-E-1321) [2,3]. 
This approach to determining $t_{\mathrm{ig}}$ is very useful in evaluation of construction materials for buildings and furniture since it provides a good first order approximation to ranking the materials resistance to ignition as a function of their thermal properties. However, it fails to provide reliable data for the critical thermodynamic and transport properties needed to develop predictive models for ignition and flame spread under conditions different to those in the test. Furthermore, the estimated $t_{i g}$ provides little insight to the ignition process when the environmental conditions are close to the critical conditions for ignition. Good examples of such environments are spacecraft and highly oxygenated environments [4]. Environmental variables become an issue and questions arise about the main hypothesis of the test methodology.

Recent studies have shown that, for many cases, ignition cannot be modeled as the heating of an inert material. The degradation process results in significant gasification of flammable gases before ignition [5]. For example, some materials are fire retardant and their pyrolysis tends to inhibit rather than enhance gas phase combustion [6]. For such class of materials, the period of this mass loss without ignition can last as long or longer than the preheating process to get to $T_{P}$. Furthermore, recent studies have noted that a critical mass flux of fuel emerging from the surface $[7,8]$ or a critical fuel concentration in the gas phase are better criteria for predicting ignition than a surface ignition temperature [1,9].

These observations have prompted more complex modeling of the degradation process that question the use of average solid and gas phase properties and have shown that the use of temperature-dependent properties can provide, for certain conditions, better correlation with the experimental ignition delay times. These refinements are reviewed in detail elsewhere [7] and will not be discussed here. More recent efforts include thermal modeling of the pyrolysis vapor generation [1,10], with both decomposition chemistry [11] and in-depth fuel migration (bubbling) [12]. The additional surface/sub-surface models seem necessary to fully describe piloted ignition.

Models that introduce degradation chemistry are more complete and require significant computation and knowledge of the surface chemistry, which is often not available for real materials. Oftentimes, critical steps in the kinetic mechanism remain uncertain and even when they are known, the kinetic constants for some or all of the reaction steps are inadequately defined. Furthermore, a proper model for fuel vapor migration in the sub-surface is also 
difficult to define. The lack of data to evaluate detailed surface chemistry and transport mechanisms indicates the need for more fundamental degradation studies before detailed surface chemistry and transport models can be confidently employed for more accurate prediction of piloted ignition. Thus far, the use of global kinetics with experimentally fitted $\mathrm{E}_{\mathrm{a}}$ and pre-exponentials is the preferred approach for incorporating degradation chemistry into solid ignition models. The fundamental experimental data on the degradation process will however assess the mechanisms that control the mass flux of fuel evolving from the degrading surface and when models of the various processes can be either neglected or simplified.

The present study uses a thermogravimetric analyzer (TGA) coupled to a quadrupole mass spectrometer (MS) to extract experimental data for a reference material, poly (methyl) methacrylate (PMMA). This data is expected to provide some clarification on the mechanisms controlling the fuel generation in the period that follows the onset of pyrolysis but precedes ignition $\left(t_{M}\right)$. The conditions to be studied are relevant to piloted ignition tests previously reported in the literature and thus provide a starting point for further investigations to build better chemistry and transport models to capture the polymer degradation process.

\section{Piloted Ignition of PMMA}

Piloted ignition tests were conducted with a $30 \mathrm{~mm}$ x $30 \mathrm{~mm}$ slab of $25 \mathrm{~mm}$ thick PMMA Type-G (Rohm and Haas). Tests were conducted by exposing the sample to a radiative heat flux originated from an electrical panel (Fig. 1). The pilot consists of an electrically heated coil of Kanthal wire placed above the sample. One surface was heated while the others were insulated.

The objective of these tests is to estimate the differences between the time to ignition $\left(t_{\mathrm{ig}}\right)$ and the time to attain the onset of pyrolysis ( $\left.\mathrm{t}_{\mathrm{P}}\right)$, thus establishing the importance of the mixing time $\left(\mathrm{t}_{\mathrm{M}}\right)$. For this purpose, type- $\mathrm{K}(0.5 \mathrm{~mm})$ thermocouples are melted into the surface of the fuel slab. The relatively large bead for the thermocouples was to avoid breaking of the bead and minimize separation from the surface when the polymeric material loses its rigidity. Separation of the thermocouples from the surface limits the reliability of thermocouple measurements for establishing the onset of pyrolysis. Three other methods are used in conjunction with the thermocouple measurements: an infrared camera, mass loss measurements, and flow visualization. An Inframetrics-13463 infrared camera views the 
surface of the fuel with a $3.399 \mu \mathrm{m}$ filter that corresponds to the emissions of the monomer (MMA). The filter allows transmission of only $25 \%$ of the emission. The camera only records a slight temperature increase until the onset of degradation. The presence of the monomer results in a sudden increase in temperature induced by the contribution of the gas. This transition was used as an indicator for the onset of pyrolysis. The experiment was set on top of a load cell and the mass loss was obtained as a function of time with a Navigator N02120 scale that provided measurements with an accuracy of $\pm 0.01 \mathrm{~g}$. The onset of pyrolysis was defined by a sudden increase in the mass loss rate. Finally, the onset of pyrolysis was determined by direct visualization of the smoke. The smoke was made visible by a light sheet originating from an SDL-7432 H1 Diode Laser that provides an output of $500 \mathrm{~mW}$ in a narrow band centered at $683 \mathrm{~nm}$. The images were recorded with a COHU 4915 CCD camera with a 685 nm filter.

The time to the onset of pyrolysis $\left(t_{P}\right)$ was recorded independently from all four different methods and tests ere repeated at least five times for each heat flux. It was observed that the discrepancy between all methods was less than $10 \%$ therefore an average of all values will be presented here. Fig. 2 shows a characteristic surface temperature history. The experimental data shows a significant departure from the predicted solution using the inert heating of a semi-infinite solid for temperatures above $285^{\circ} \mathrm{C}$. Beyond that point, the analytic solution over-predicts the temperature rise, which suggest an endothermic degradation process. The glass transition temperature for PMMA is $\sim 105^{\circ} \mathrm{C}$ therefore a major change in thermophysical properties being responsible for this departure was discarded. Ignition is represented by a sudden increase in the surface temperature $\left(\mathrm{t}_{\mathrm{ig}} \approx 1550 \mathrm{~s}\right)$. It is important to note that Fig. 2 shows that $t_{M}\left(=t_{i g}-t_{P}\right)$ is slightly larger than $t_{P}(850 \mathrm{~s} v s .700 \mathrm{~s})$.

The temperature for the onset of pyrolysis $\left(285^{\circ} \mathrm{C}\right)$ remained consistent and was deemed as the characteristic pyrolysis temperature $\left(T_{P}\right)$. $t_{P}$ and $t_{i g}$ were obtained for a wide range of heat fluxes, and the average results are presented in Fig. 3. As indicate in Fig. 3, there is a significant discrepancy between the two times, which indicated that the mixing time can not be neglected in ignition models. Furthermore, it can be easily shown that $t_{M}$ is inherently linked to the flow characteristics [5], and thus deriving global thermal properties from the ignition delay times will result in values that are dependent on the environmental conditions of the test. This might be of little significance to the relative ranking of materials, as stipulated by the ASTM-E- 
1321 standard [3] and later validated by Long et al. [1], but these discrepancies could be of relevance if these properties are used to model piloted ignition delay times.

\section{Thermal Degradation of PMMA}

The above observations show that adequate modeling of ignition delay times requires a proper estimation of the mixing time. Complete modeling of the mixing process that leads to formation of flammable mixtures requires quantification of both the rate and products of surface degradation chemistry as well as the different parameters that control the migration of gas phase degradation products through the molten material [11,12]. Although the work presented here does not determine these parameters and constants, it does establish the significance of transport (heat and mass) and chemistry in the degradation of PMMA.

Polymer degradation was measured with a TGA, (ThermoCahn model 2131). The products evolved were analyzed by a quadrupole MS (VG Gaslab300). The evolved gases from the PMMA samples were transferred through a capillary tube packed with fused silica. The transfer line was heated and maintained at temperature of $150^{\circ} \mathrm{C}$ to prevent condensation of water and heavier off-gases, flow through the TGA was fixed at $90 \mathrm{ml} / \mathrm{min}$.

An industrial grade PMMA, commercial plexiglass type G (Rohm and Hass) was used for this study. The samples were obtained by grating larger pieces to particles of approximately $0.5 \mathrm{~mm}$ in diameter. The diameter was chosen based on the observation reported by Cordova et al. [5] that, even for heat fluxes above $40 \mathrm{~kW} / \mathrm{m}^{2}$, the thickness of the visible molten layer of a PMMA plate is greater than $1 \mathrm{~mm}$. This choice for characteristic size is important since this will likely impact the influence of mass transport effects. Therefore, the characteristic size of the particle was set to be comparable to that of the degrading fuel in the ignition tests. The individual PMMA particles consist of chains of approximately 130,000 molecules and approximately $90 \mathrm{mg}$ of material is spread over the surface of the container. The large sample size is necessary to obtain a good signal to noise ratio for the mass spectrometer.

For the determination of kinetic constants, it is critical to use smaller particles and samples, as reported elsewhere $[13,14]$. For this purpose, reference tests where conducted with powder PMMA that consisted of pure spheres of smaller diameter (approximately $0.1 \mathrm{~mm}$ )

obtained from the Aldrich Company. The results will not be discussed here since they significantly departed from those obtained from the grated samples. The difference between 
the chemically pure PMMA and the industrial samples can be attributed to the chemical additives of the industrial PMMA that included parting agents as well as ultraviolet absorbers. It is important to note that the thermo-grams for both industrial and powder PMMA also departed significantly from the results reported in references $[13,14]$. Since the variances in the chemical composition of all three Type-G PMMA samples could not be established, the study of these differences was considered beyond the scope of this work.

An initial set of TGA experiments was conducted with pure $\mathrm{N}_{2}$ atmospheres. The normalize weight and the weight loss rates for different heating rates are presented in Fig. 4. It is important to note that the heating rates for ignition tests are never larger than $5^{\circ} \mathrm{C} / \mathrm{min}$. The weight loss rate curves with the smooth single peak, as shown in Fig. 4, suggest a one-step reaction for all heating rates. As the heating rate increases, the temperature at which maximum weight loss rate occurs increases, and the increase in the temperature of peak weight loss rate can be used to derive an effective global $\mathrm{E}_{\mathrm{a}}(184 \mathrm{~kJ} / \mathrm{mol})$ for the degradation process.

More information of the degradation process can be gathered from the mass spectra curves from the real-time MS evolved gas analysis. Three molecular weight to charge ratios $(\mathrm{m} / \mathrm{z}=39,41$, and 55) are presented in Fig. 5. The $\mathrm{m} / \mathrm{z}$ values in Figure 5 represent molecular fragments associated with MMA monomer fragmentation and thus the ion intensities curves for each $\mathrm{m} / \mathrm{z}$ in Figure 5 show a similar shape and qualitatively represent the release of MMA monomer from the PMMA particles. For the low heating rate value of $1^{\circ} \mathrm{C} / \mathrm{min}$, the $\mathrm{m} / \mathrm{z}$ curves show a clear peak, which correlates quite well with the peak in the weight loss rate. However, for the higher heating rate, the ion intensities for the key MMA fragments shows a rapid jump in evolved gases at $420^{\circ} \mathrm{C}$ followed by an equally rapid decay in the same ion intensities at $480^{\circ} \mathrm{C}$. The rapid increase in MMA volatilization at the higher heating rates suggests one of two scenarios: 1) a high activation energy process beginning at approximately $420^{\circ} \mathrm{C}$ but mass transport limits the rate of reaction or 2) a rapid softening of the particles at $420^{\circ} \mathrm{C}$ that provides for rapid removal of trapped vapors inside the polymer particles. The mass transport limitation of the MMA production are likely due to inadequate transport of MMA vapors away from the polymer surface, since it is expected that the pure $\mathrm{N}_{2}$ does not play a substantial role in the PMMA degradation kinetics. This apparent mass transport limitation was observed for all heating rates $>1{ }^{\circ} \mathrm{C} / \mathrm{min}$. However, for $1^{\circ} \mathrm{C} / \mathrm{min}$, shown in Fig. 5, the rapid jump in reaction rates and apparent mass transport limitations are not observed and both the weight-loss and ion 
intensity curves suggest that the process can be fairly well modeled by a one-step global mechanism. The impact of the heating rate on both the shape and peak location of the weight loss curves and the MMA vapor release suggests that the pyrolysis process is in some way selfpromoting. This can be explained both by the reactions causing an increase in surface area as well as pyrolysis causing a local breaking of chains and thus an increase in exposed ends with enhanced activity for volatilization.

The presence of $\mathrm{O}_{2}$ in the gas phase significantly reduces the temperature at which the degradation process is initiated. Experiments were conducted with 5\%,10\%, 15\% and 21\% $\mathrm{O}_{2}$ in $\mathrm{N}_{2}$. Fig. 6 shows how the initiation temperature for PMMA degradation, i.e. $\mathrm{T}_{\mathrm{P}}$ (which is not necessarily $\mathrm{T}_{\mathrm{ig}}$ ), decreases by up to $100^{\circ} \mathrm{C}$ with increasing $\mathrm{O}_{2}$ content up to about $10 \% \mathrm{O}_{2}$. Above $10 \% \mathrm{O}_{2}$, increasing $\mathrm{O}_{2}$ mole fraction does not seem to significantly lower $\mathrm{T}_{\mathrm{P}}$. Furthermore, the same sensitivity of $\mathrm{T}_{\mathrm{P}}$ to heating rate observed in pure $\mathrm{N}_{2}$ environments is observed for the $\mathrm{O}_{2}$ containing environments. This variation in heating rate is extremely significant for modeling piloted ignition because it suggests that temperature is not the only factor governing the pyrolysis and degradation processes responsible for piloted ignition. Typical degradation temperatures for PMMA have been reported to be $>300^{\circ} \mathrm{C}[13,14]$ and it is not surprising that these values have been unsuccessful in predicting piloted ignition. Heating rate and associated transport effects that can only be established when analyzing the degradation products might lead to a bias for these values.

The characteristic pyrolysis temperatures established during piloted ignition tests $\left(285^{\circ} \mathrm{C}\right)$ fall somewhere in between the two temperature ranges. This suggests that a combination of inert and oxidative pyrolysis might provide the gaseous fuel necessary for ignition. This merits a closer observation of the degradation of PMMA in an oxidative atmosphere. Fig. 7 shows evolution of the weight loss rate as a function of temperature for 5\% and $21 \% \mathrm{O}_{2}$ in $\mathrm{N}_{2}$ - in each case for two different heating rates. The weight loss rate curves show that the onset of degradation in the oxygenated environments occurs at approximately $250^{\circ} \mathrm{C}$. As the temperature increases, the weight loss rate increases until a sudden increase in the rate is observed at $\mathrm{T} \approx 360^{\circ} \mathrm{C}$. This initial step in the degradation process has been previously described by Hirata et al. [14]. Degradation follows with a weaker increase in the weight loss rate. The first rate change can be attributed to the limited amount of oxygen that can diffuse into the material and that is necessary for the oxidative pyrolysis. Nevertheless, this 
process seems to contribute to the gasification of the material since the weight loss rate continues to increase. A second rapid increase in weight loss rate is observed at $\mathrm{T} \approx 360^{\circ} \mathrm{C}$, which is clearly associated with a second step in the polymer degradation. The cause for this second step is uncertain, but it is clear that oxidative attack of the surface influences this process because a similar peak was observed at much higher temperatures $\mathrm{T} \approx 420^{\circ} \mathrm{C}$ in the pure $\mathrm{N}_{2}$ environments. The intensity of this second peak seems to increase with $\mathrm{O}_{2}$ concentration and decrease with heating rates. Thus, $\mathrm{O}_{2}$ transport to the surface must be limiting the degradation reactions for $\mathrm{T}<360^{\circ} \mathrm{C}$ and the increase in weight loss rate might be due to an increase in diffusivity resulting from the temperature increase. This is important since piloted ignition temperatures for conditions similar to those of ASTM-E-1321 are generally lower than $360^{\circ} \mathrm{C}$ (Fig. 2).

A plateau that is more evident for the lower heating rates follows the second inflection point. This phenomenon seems to contradict the conclusion that at this stage mass transport of oxygen is the limiting parameter of degradation, but might be the result of two competing mechanism, in-depth inert degradation and surface oxidation. As the temperature increases, inert degradation becomes dominant and a second sudden increase in the weight loss rate is observed between $430-450^{\circ} \mathrm{C}$. These temperatures correspond well with those presented in Fig. 4 and 5.

Figure 8 shows some characteristic $\mathrm{m} / \mathrm{z}$ ratios for air. The conditions are the same as the mass loss rate curves presented in Fig. 7. The $\mathrm{m} / \mathrm{z}$ ratios provide little insight on the initiation of oxidative pyrolysis since the MS sensitivity was unable to pick up the volatilization products due to the low production rates for $\mathrm{T}<300^{\circ} \mathrm{C}$. The evolution of the $\mathrm{m} / \mathrm{z}$ ratios for $3^{\circ} \mathrm{C} / \mathrm{min}$ confirms conclusions derived from Fig. 7. Furthermore, it shows that the final peak is actually truncated as during inert degradation. It is of extreme importance to point that both steps of the degradation are impacted by transport. Mass transport in and out of the fuel is a phenomenon that is not well understood [12] but all too often neglected. The $\mathrm{m} / \mathrm{z}=44$ curve representative of $\mathrm{CO}_{2}$, is presented in Fig. 8 is not noticed in inert degradation and thus shows that the presence of $\mathrm{O}_{2}$ is playing a significant role in the products of the degradation and thus in the formation of a potentially flammable mixture. Thus, the importance of environmental $\mathrm{O}_{2}$ concentration even for piloted ignition studies is critical since $\mathrm{O}_{2}$ will impact not only the 
pyrolysis initiation temperature but also the degradation gases that will go into the formation of the flammable gas-phase mixture.

\section{Conclusions}

Degradation of Type-G PMMA (Rohm and Haas) in pure $\mathrm{N}_{2}$ and oxygenated atmospheres was studied. Tests conducted with a PMMA slab heated by a radiant panel showed that:

- Degradation prior to piloted ignition can account for more than $50 \%$ of the ignition delay time.

The degradation of the polymer was measured with a TGA and a MS analyzed the products evolved. It can be concluded that:

- Mass transport limitations sometimes not observable through mass loss curves are indicated as abrupt changes in the evolved gas profiles. This indicates the importance of coupling TGA measurements with evolved gas analysis for detecting mass transport limitations.

- Mass loss measurements suggested that degradation of industrial PMMA in pure $\mathrm{N}_{2}$ can be modeled as a single-step reaction, but further analysis of the evolved gases showed that mass transport effects affected the degradation process.

- The presence of $\mathrm{O}_{2}$ shifted the degradation to lower temperatures. The analysis of the evolved gases suggested a two-step reaction and again revealed mass transport effects. Oxygen transport to the surface limits the degradation reactions for $\mathrm{T}<350^{\circ} \mathrm{C}$. For $350^{\circ} \mathrm{C}<\mathrm{T}<430^{\circ} \mathrm{C}$, inert and oxygen promoted degradation compete with inert degradation becoming dominant for $\mathrm{T}>430^{\circ} \mathrm{C}$.

The present results have shown that, at least for PMMA, modeling of piloted ignition requires not only an appropriate definition of the kinetic constants but also adequate modeling of oxygen transport into the material and gasified combustibles out of the sample.

\section{Acknowledgements}

This work was funded by NASA Glenn under Grant \# 31961 and the TGA/MS used for these experiments was purchased with support from the National Science Foundation, CTS 
Grant \# 99-75189. The authors wish to thank the insightful comments of Drs. Howard Ross and Farley Fisher.

\section{References}

1. Long, R.T., Torero, J.L., Quintiere, J.G. and Fernandez-Pello, A.C., "Scale and Transport Considerations on Piloted Ignition of PMMA," Sixth Intl. Symp. Fire Safety Science, pp.567-578, 1999.

2. Quintiere, J. G., "A simplified theory for generalizing results from a radiant panel rate of flame spread apparatus", Fire Mater., 5:52 (1981).

3. ASTM, ASTM E 1321-93, "Standard test method for determining material ignition and flame spread properties”, Annual Book of ASTM Standards, 04.07, 1996.

4. Fernandez-Pello, A.C., Walther, D.C., Cordova, J.L., Steinhaus, T., Quintiere, J.G., Torero, J.L., and Ross, H., Space Forum, 6:237 (2000).

5. Cordova, J.L., Walther, D.C., Torero, J.L. and Fernandez-Pello, A.C., Combust. Sci. Tech., 164:253 (2001).

6. Tewarson, A., Abu-Isa, I.A., Cummings, D.R., LaDue, D.E., "Characterization of the Ignition behavior of Polymers Commonly Used in the Automotive Industry," Sixth Intl. Symp. on Fire Safety Science, pp.991-1002, 1999.

7. Atreya, A., "Ignition of Fires," Phil. Trans. R. Soc. Lond. , 356,:2787 (1998).

8. Drysdale, D. D. and Thomson, H.E., Fire Safety J., 5:167 (1989).

9. Cordova, J. L. and Fernandez-Pello, A. C., Combust. Sci. Tech., 156:271 (2000).

10. Quintiere, J. G. and Iqbal, N. "Approximate Integral Model for the Burning Rate of a Thermoplastic-Like Material," Fire Mater., 18:89 (1994).

11. Zhou, Y. and Fernandez-Pello, A.C., Combust. Theor. Model., 4:477 (2000).

12. Butler, K.M, “A mixed layer pyrolysis model for polypropylene," Sixth Intl. Symp. on Fire Safety Science, pp.313-324, 1999.

13. Kashiwagi, T., Hirata, T. and Brown, J.E., Macromolecules, 18:131 (1985).

14. Hirata, T., Kashiwagi, T. and Brown, J.E., Macromolecules, 18:1410 (1985). 


\section{FIGURE CAPTIONS}

Figure 1 - Schematic of the experimental setup used to obtain the ignition delay time $\left(t_{i g}\right)$ and the time for the onset of pyrolysis $\left(t_{\mathrm{P}}\right)$.

Figure 2 - Characteristic surface temperature history corresponding to an experiment conducted with $\dot{\mathrm{q}}_{\mathrm{e}}^{\prime \prime}=12 \mathrm{~kW} / \mathrm{m}^{2}$. Two curves are shown, one corresponding to the semiinfinite solid solution under the assumptions given by Quintiere [2] and with global properties as defined by reference [5].

Figure 3 - Characteristic ignition delay times $\left(t_{i g}\right)$ and times to the onset of pyrolysis $\left(t_{P}\right)$ for PMMA and a wide range of external heat fluxes.

Figure 4 - Weight loss and weight loss rate curves for different heating rates in pure $\mathrm{N}_{2}$ for 0.5 mm samples of industrial-grade PMMA.

Figure 5 - Weight loss rate and molecular weight to charge ratios for industrial-grade PMMA degradation in a pure $\mathrm{N}_{2}$ atmosphere. The thinner lines correspond to $5^{\circ} \mathrm{C} / \mathrm{min}$ heating rates while the thicker lines to $1^{\circ} \mathrm{C} / \mathrm{min}$.

Figure 6 - Onset of degradation for different oxygen concentrations and heating rates. The intercept between the horizontal (initial mass of the sample) and a tangent to the weight loss curve at the maximum weight loss rate temperature defines the onset of degradation. The outlying data point for $5 \%$ oxygen is probably due to moisture in the sample.

Figure 7 - Weight loss rate curves for air (thick line) and 5\% $\mathrm{O}_{2}$ degradation (thin line). Two heating rates are presented for each oxygen concentration.

Figure 8 - Weight loss rate and molecular weight to charge ratios for PMMA degradation in an oxygenated atmosphere. The thin lines correspond to $3^{\circ} \mathrm{C} / \mathrm{min}$ heating rates while the thick lines to $5^{\circ} \mathrm{C} / \mathrm{min}$. 


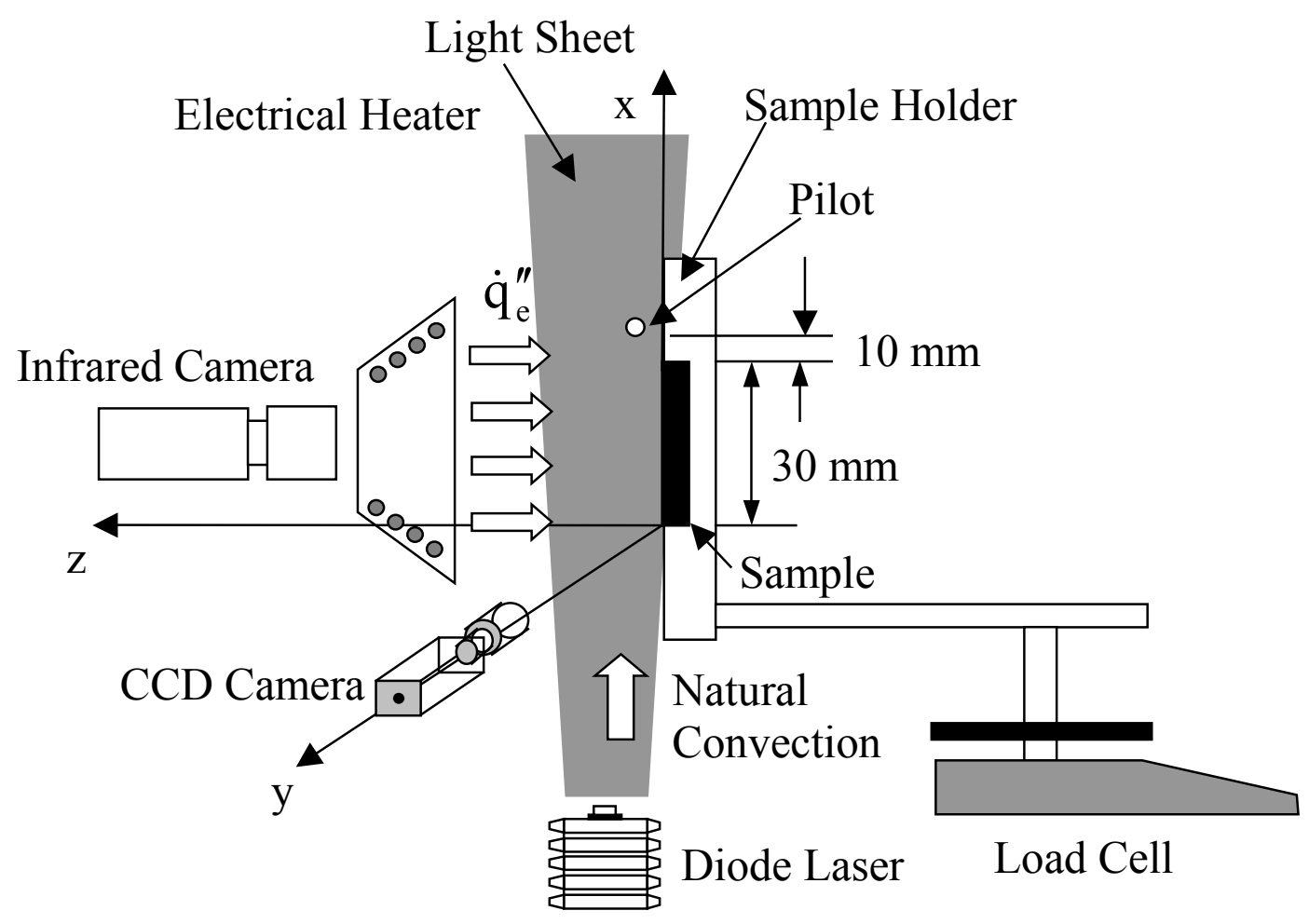

Figure 1 


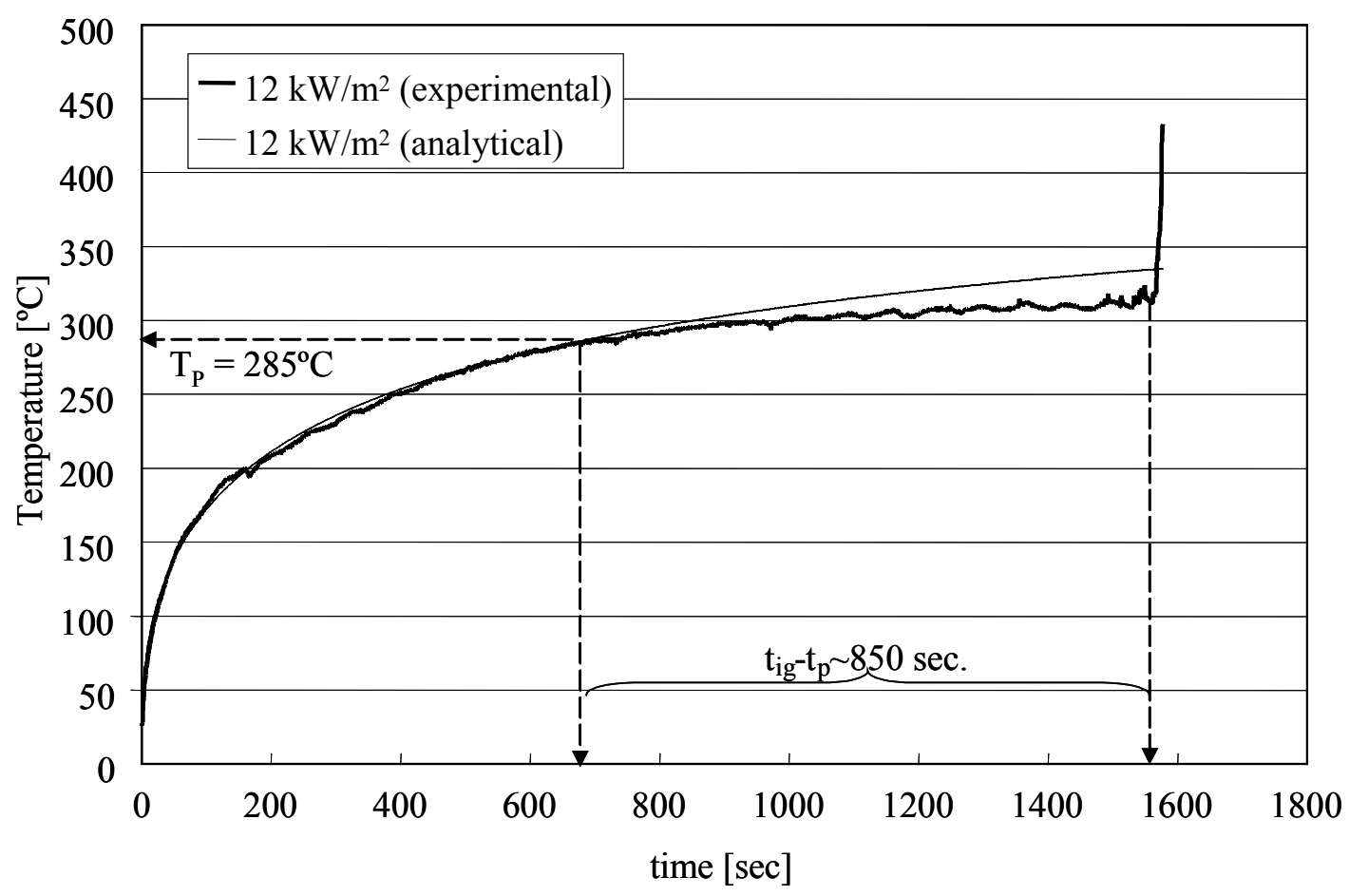

Figure 2 


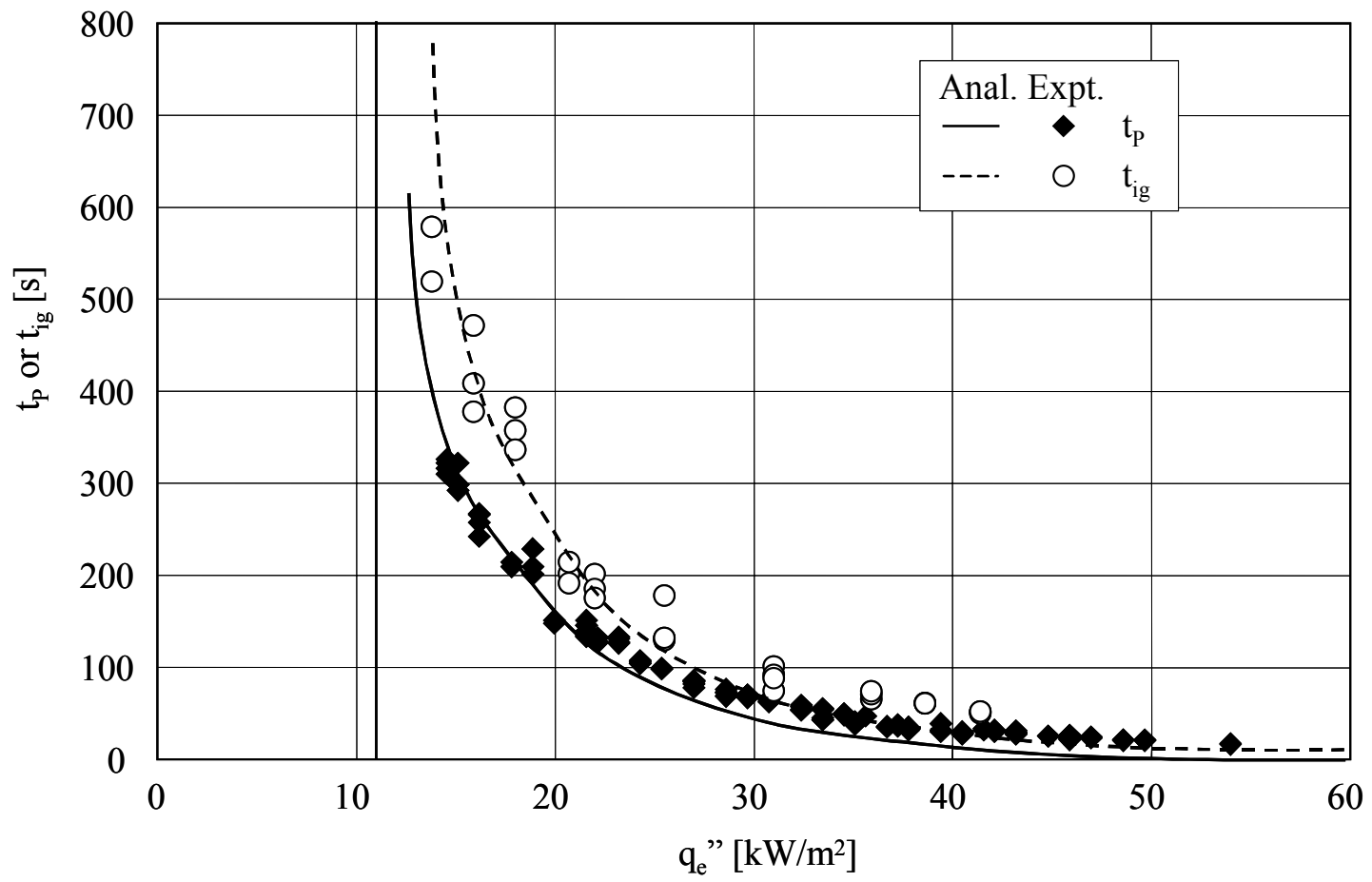

Figure 3 


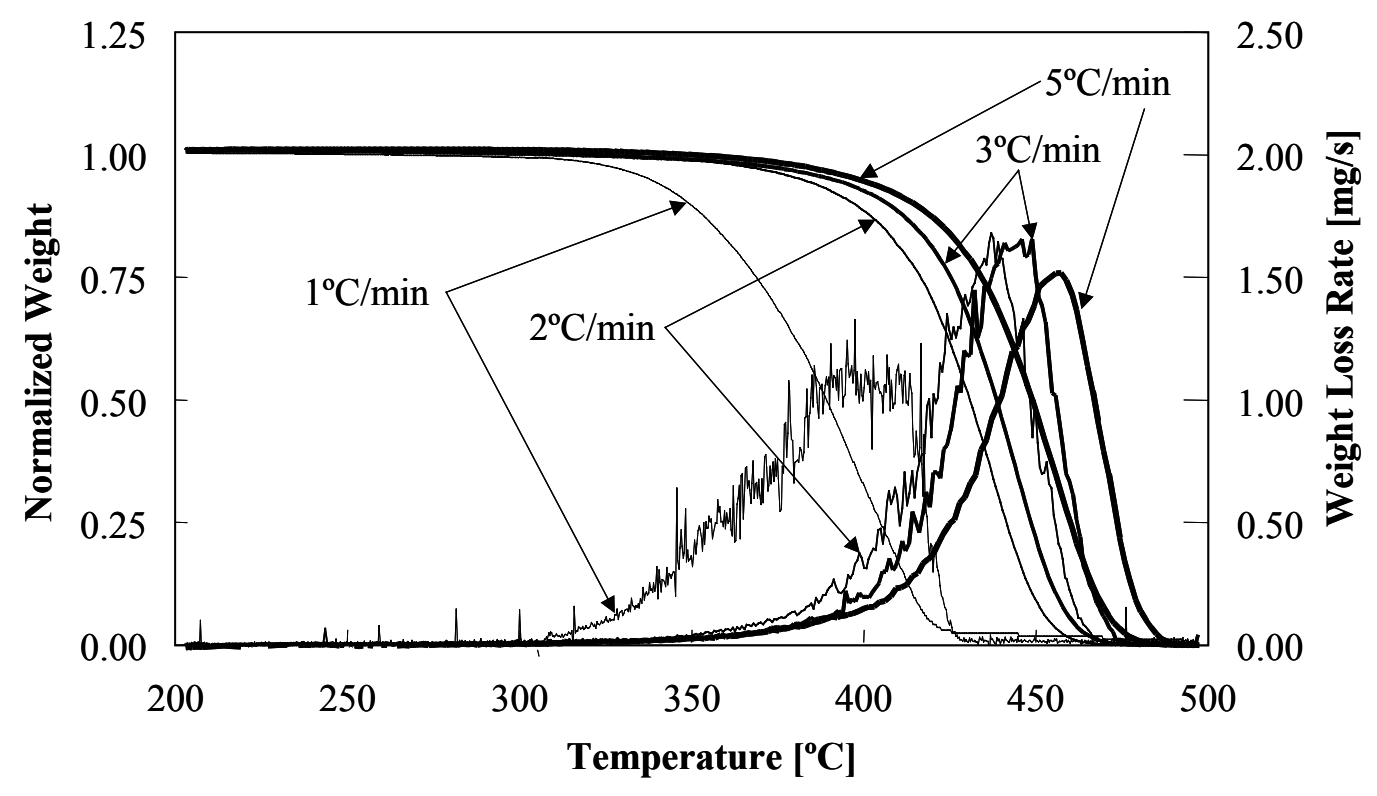

Figure 4 


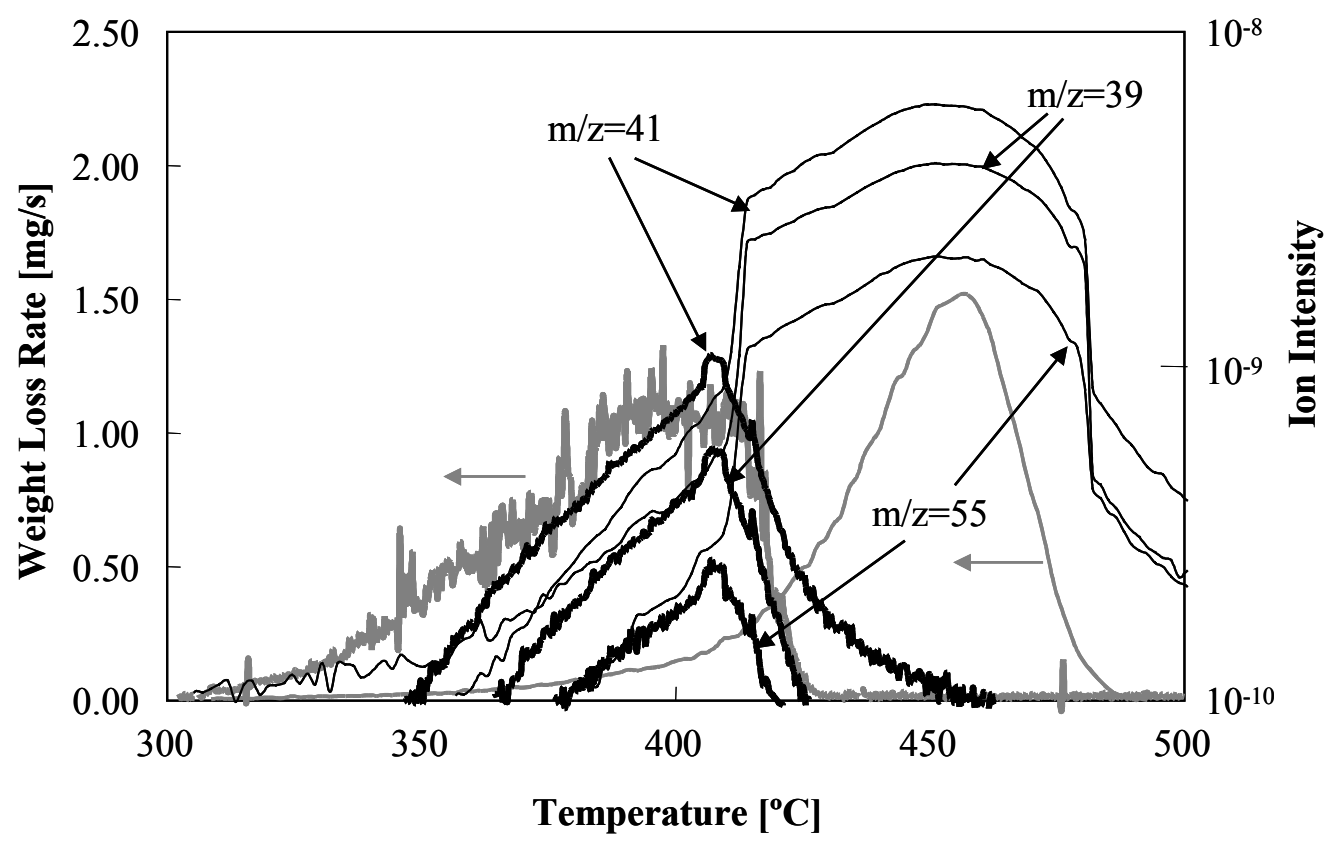

Figure 5 


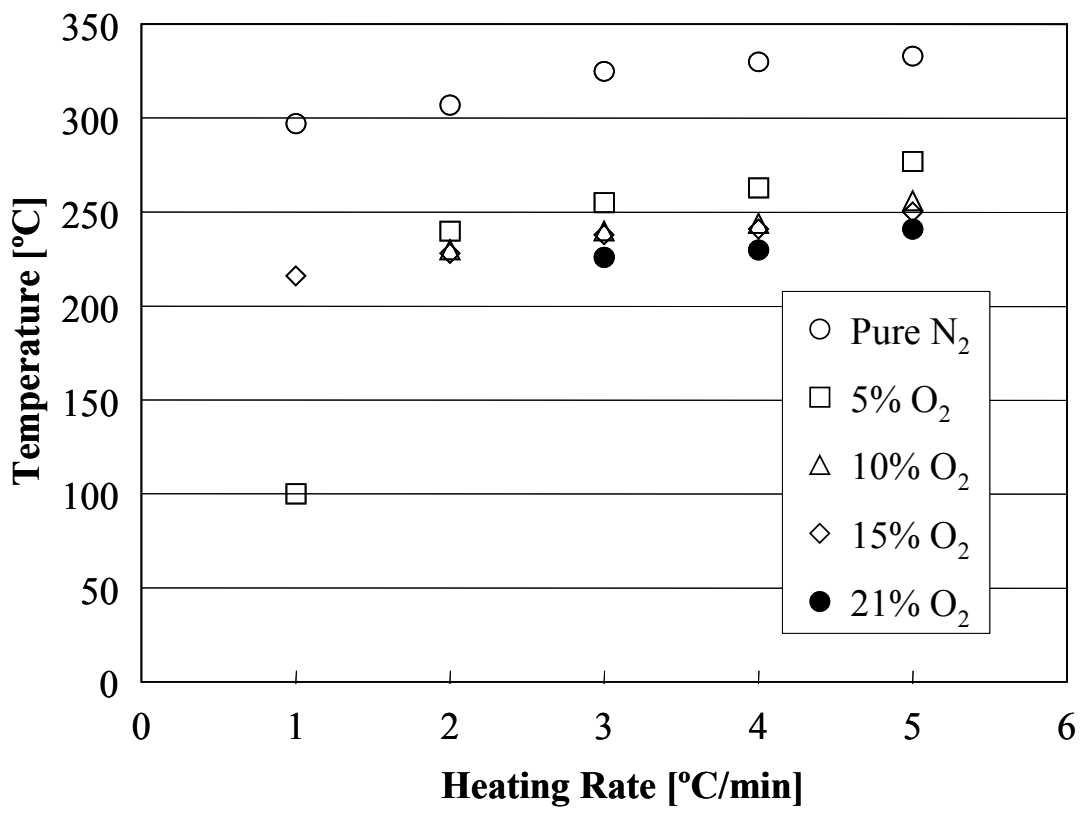

Figure 6 


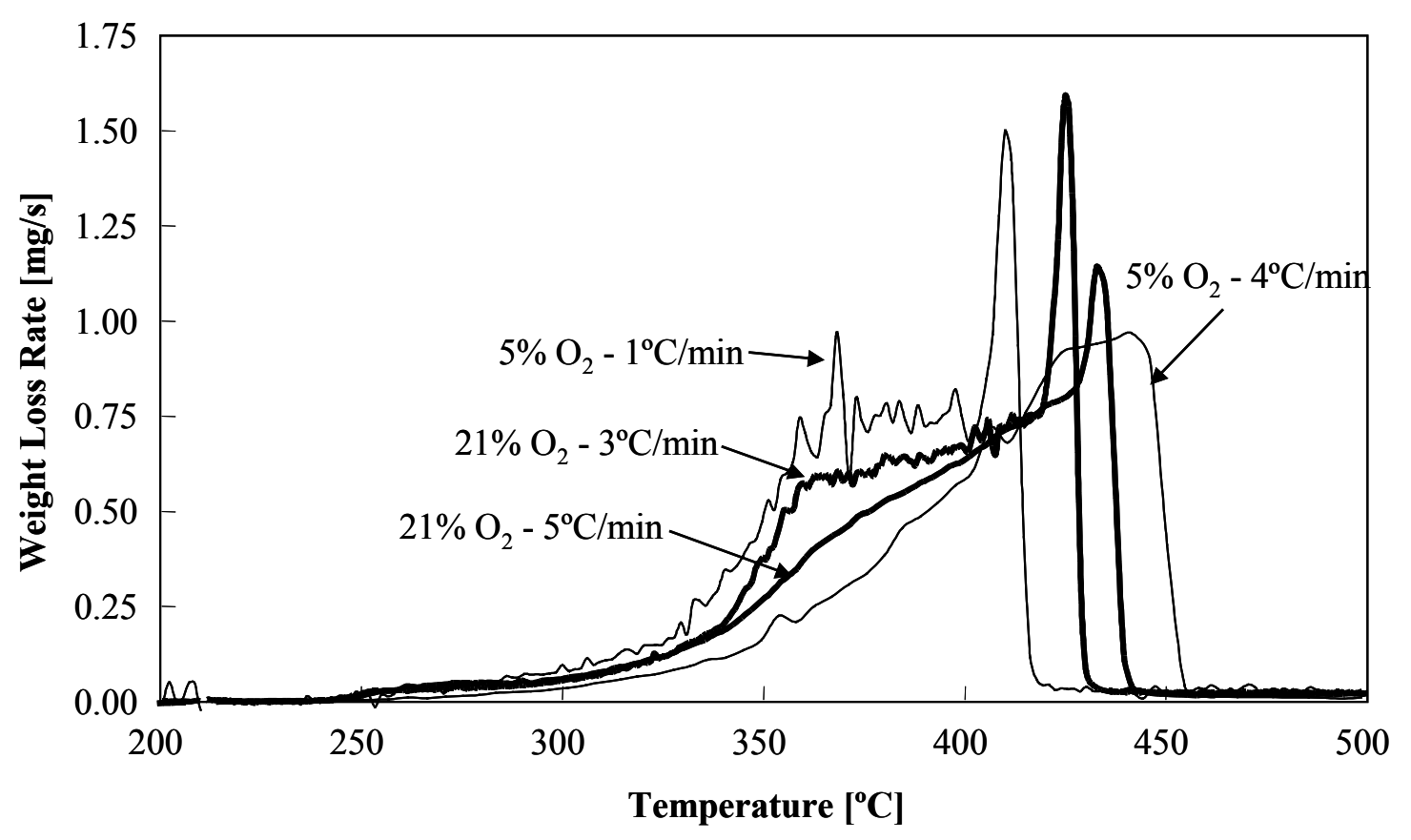

Figure 7 
Dakka, S.M., Jackson, G. S. and Torero, J.L., Mechanisms Controlling the Degradation of Poly(methyl methacrylate) Prior to Piloted Ignition Proceedings of the Combustion Institute, 29, 281-287, 2002.

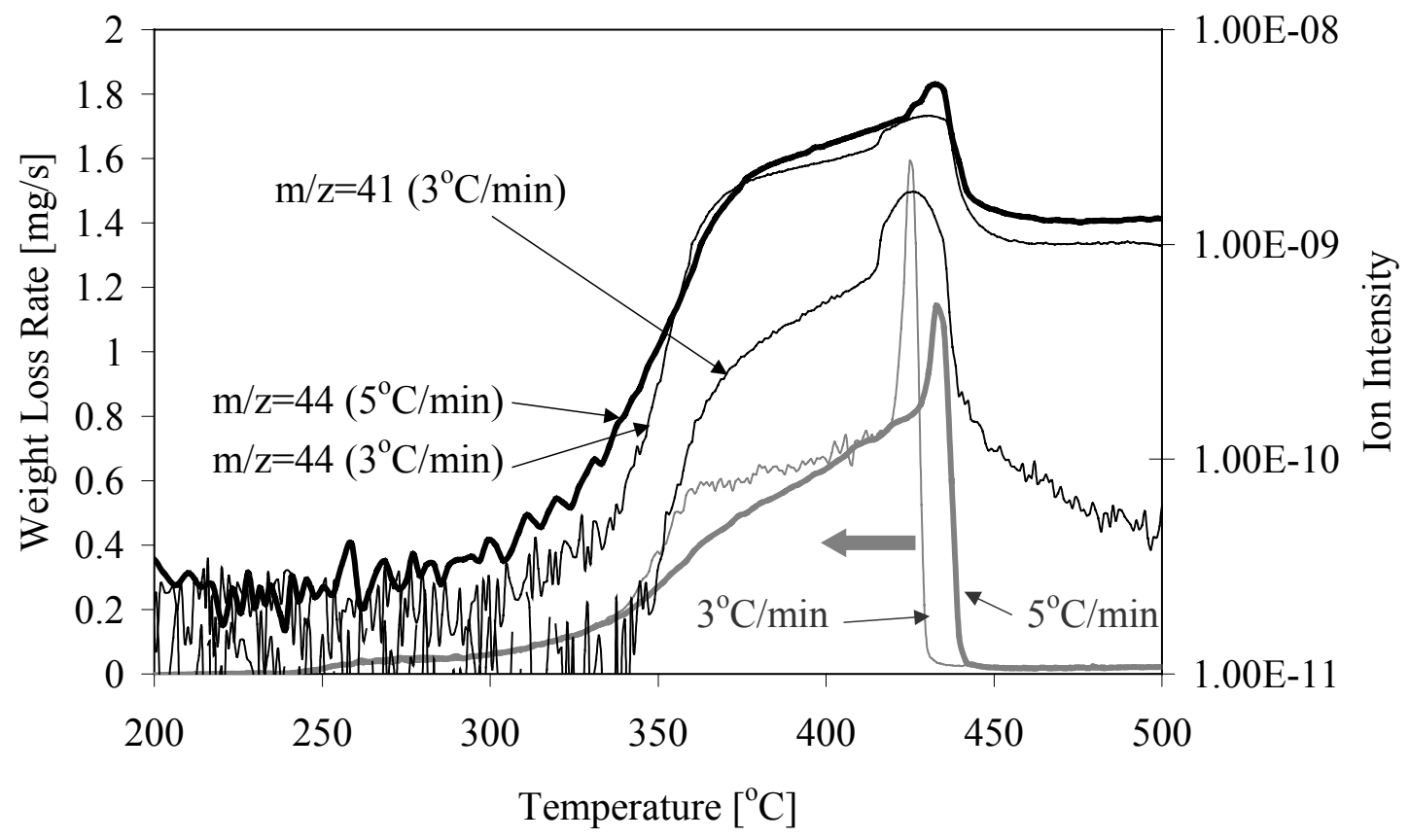

Figure 8 